\title{
Structure and Temporal Variability of Mediterranean Water in Hydrological and Marine Seismic Data South of Portimao Canyon (Gulf of Cadiz), from 1999 to $2002^{*}$
}

\author{
Elise Quentel $^{1}$, Xavier Carton ${ }^{2}$, Marc Andre Gutscher ${ }^{1}$ \\ ${ }^{1}$ LDO, IUEM/UBO, Technopole Brest Iroise, Plouzane, France \\ ${ }^{2}$ LPO, IUEM/UBO, 6 Avenue Le Gorgeu, Brest, France \\ E-mail:xcarton@univ-brest.fr \\ Received April 22, 2011; revised June 19, 2011; accepted July 23, 2011
}

\begin{abstract}
Hydrological and marine seismic data, collected in the Gulf of Cadiz (respectively in July 1999, 2000, 2001 and 2002, and in April 2000 and 2001) are analysed to reveal the various structures of Mediterranean Water (MW). Both the hydrological and seismic data clearly identify the MW undercurrents on the Iberian slope, detached MW eddies (meddies and a cyclone) and smaller fragments of MW (filaments and small eddies). Seismic reflectivity and synthetic reflectivity computed from hydrology, indicate that strong acoustic reflectors, associated with $8-64 \mathrm{~m}$ thick homogeneous water layers, are found above and below meddies and filaments, around the MW undercurrents, but mostly in the lower part of cyclones and below submesoscale eddies. Reflectors are also observed in the near surface layers where thermohaline contrasts are quite pronounced. The successful use of seismic data to locate submesoscale MW structures, superior to that of hydrology, is related to the improved horizontal resolution.
\end{abstract}

Keywords: Mediterranean Water, Eddies, Undercurrent, Layering, Hydrological Data, Seismic Reflectivity, Submesoscale Structures

\section{Introduction}

Mediterranean Water (hereafter MW), which flows out of the Straits of Gibraltar (near $6 \mathrm{~W}$ ) at $150-300 \mathrm{~m}$ depths, cascades down the continental slope east of the Gulf of Cadiz, and mixes with surrounding waters [1]. These surrounding waters have temperatures decreasing with depth, so that the uppermost MW remains warmer than the lower part of the outflow. This inhomogeneous mixing, as well as the influence of transverse canyons on the continental slope, separate the MW outflow into three density-adjusted undercurrents of MW upstream of $8 \mathrm{~W}$ : the shallow one at $400-600 \mathrm{~m}$ depth, the upper one at $800 \mathrm{~m}$ and the lower one at $1200 \mathrm{~m}$ [2-5]. Heading westward along the Iberian continental slope, the upper and lower undercurrents encounter the Portimão Canyon which destabilizes them, producing meanders, filaments and eddies [4-6]. At this location, two undercurrents with

The GO project was funded by the 6th EU Framework for research and Development. This work was supported by SHOM under PEA 012401 and by UBO under LPO projects. respective temperature and salinity maxima of $13.5^{\circ} \mathrm{C}$ and 36.4 and $12.5^{\circ} \mathrm{C}$ and 36.6 have regularly been observed at 800 and $1200 \mathrm{~m}$ depths. In this region, a deep core (at depths of $1300-1600 \mathrm{~m}$ ) has also been observed [7]. Farther downstream, the upper and lower MW undercurrents veer around Cape Saint Vincent, again producing eddies (with slightly weaker thermohaline characteristics; [8]). MW undercurrents then flow northward and can still be clearly identified northwest of the Iberian Peninsula. Mediterranean Water eddies are also produced near the Estremadura Promontory [9] and near Cape Ortegal $[10,11]$. When meddies are formed near Portimão Canyon or Cape Saint Vincent, they can drift southwestward under the influence of the planetary vorticity gradient, or cyclonically in the Gulf of Cadiz when they pair with cyclones $[12,13]$.

The present study concentrates on the hydrological and dynamical properties of Mediterranean water south of Portimão Canyon as measured during several cruises of the SEMANE program (Suivi des Eaux Méditerranéennes en Atlantique Nord-Est-Following the Medi- 
terranean Waters in the Northeastern Atlantic Ocean), and on the signature of this water mass in seismic reflection data of the SISMAR (Etude SISmique de la marge MARocaine) and TGS-NOPEC surveys. This study aims at characterizing the MW south of Portimão canyon, observed during the SEMANE, SISMAR and TGS-NOPEC cruises, at identifying their origin and at presenting the hydrological characteristics associated with the strong reflectors observed in the seismic data $[14,15]$.

\section{Data Acquisition and Processing}

The SEMANE program was carried out mostly by the French Navy Oceanographic and Hydrographic Service (SHOM) and by the French Institute for Sea Research (IFREMER) from 1995 until 2002. Their objectives were to map MW undercurrents and eddies south of Portugal, and to track these eddies with drifters. A CTD section was performed yearly from 1999 until 2002 (in July) along $8^{\circ} 20^{\prime} \mathrm{W}$, and lowered acoustic Doppler current profiling (L-ADCP) was performed on the 1999 and 2000 sections. The 2000 and 2001 sections were supplemented with casts of XBTs and XCTDs (expendable, temperature, or temperature and salinity, probes). The horizontal distance between stations along the section was about 5 nautical miles (NM) on the continental slopes and $10 \mathrm{NM}$ in the deeper region. The vertical resolution was better than $1 \mathrm{~m}$. The accuracy of the CTD data was $+/-0.002^{\circ} \mathrm{C}$ for temperature and $+/-0.005$ in salinity. The vertical resolution of CTD data before processing was $4 \mathrm{~cm}$ (velocity of the probes equal to $1 \mathrm{~m} / \mathrm{s}$, and frequency of the sampling equal to $24 \mathrm{~Hz}$ ), and 0.7 $\mathrm{m}$ after processing. For the L-ADCP, the signal was averaged over $8 \mathrm{~m}$ bins and the accuracy on velocity was about $2.5 \mathrm{~cm} / \mathrm{s}$ for a $2500 \mathrm{~m}$ depth profile. The accuracy of XBT and XCTD probes was $+/-0.01^{\circ} \mathrm{C}$ and $+/-0.03$ in salinity.

The multi-channel seismic (MCS) profile was acquired during the SISMAR cruise, by R/V Nadir in April 2001. The aim of this cruise was to image the deep structures of the Iberian and Morocco margins with a 360 channel, $4.5 \mathrm{~km}$ long streamer and a 4805 cubic inch tuned air gun array. Shot spacing ranged from $75 \mathrm{~m}$ (for purely MCS profiles) to $150 \mathrm{~m}$ (for joint OBS and MCS profiles). This provided 30- and 15-fold CDP coverage, respectively. Thus, CDP spacing was $6.25 \mathrm{~m}$ for the MCS only profiles and $12.5 \mathrm{~m}$ for the joint profiles. The sampling rate was $4 \mathrm{~ms}$ in all cases. The frequency of the sound sources was between 5 and $60 \mathrm{~Hz}$. Both the sampling rate and the frequency provided a vertical resolution of about $6 \mathrm{~m}$ [16]. One MCS profile of this cruise and two commercial profiles (TGS-NOPEC - April 2000) located across the Gulf of Cadiz and near $8^{\circ} 20^{\prime} \mathrm{W}$ were processed. The TGS-NOPEC commercial cruise had a source receiver offset of $144 \mathrm{~m}$, a group spacing of 12.5 $\mathrm{m}$, receiver depth of $10 \mathrm{~m}$, a source depth of $7 \mathrm{~m}$ and a 480 channel, $6 \mathrm{~km}$ long streamer. According to the typical processing sequence [17], we applied a low pass filter on the seismic data. Since the direct wave disturbed the signal at the surface layer, its removal was important. We used an eigenvector filter coupled with a low cut filter for direct wave removal. For more accurate removal, we used a novel application of an eigenvector filter, which linearly moves out traces based on previous work on multiple suppression [18]. The processed hydrological sections along $8^{\circ} 20^{\prime} \mathrm{W}$, in salinity, temperature and velocity of July 1999 to 2002 are compared here to the seismic sections in the same area.

\section{Data Analysis}

Figure 1 presents the location of the SEMANE and SISMAR sections in the Gulf of Cadiz (south of Portimão Canyon). They are not coincident in space nor in time, but they show qualitatively similar features. These features are the following.

First, one consistently observes a layer marked by a positive anomaly of 0.5 in salinity whatever the year, and throughout the Gulf between 800 and 1400 m depths. In seismic data, one also observes intense acoustic reflection between 800 and $1400 \mathrm{~m}$ depths, all across the Gulf. This continuous anomaly is the diffusive tongue of Mediterranean Water, due to the turbulent mixing of this water with ambient Atlantic Water. This turbulent mixing results from mesoscale and submesoscale features which have detached from the MW undercurrents. These features appear both on the 1999, 2001 and 2002 hydrological sections and on the MCS profile (SISMAR 23).

In the SEMANE 1999 data, hydrological and LADCP data allowed the identification of a meddy between $\mathrm{km}$ 230 and 310 , with a 36.4 salinity maximum near $1200 \mathrm{~m}$ depth. Its velocity signal is most intense between 700 and $1600 \mathrm{~m}$ depths. Above the meddy, the velocity signature is more turbulent. Below it, lies a deep eastward current (near $2500 \mathrm{~m}$ depth). A cyclone is located between $\mathrm{km} 145$ and 215. It is shallower and has a 36.2 salinity maximum. It has a strong associated velocity from the surface down to $1600 \mathrm{~m}$ depth, and the corresponding current signature, though slightly shifted south, is still visible below. The temperature (not shown) and salinity of the meddy-cyclone pair indicate that their origin lies between Portimão Canyon and Cape Saint Vincent. Between these two eddies (near km 215 - 225) lies a narrow salinity maximum, which is a filament. It was identified by Carton et al. [12] using complementary XBT and XCTD data in the Gulf. This filament origi- 

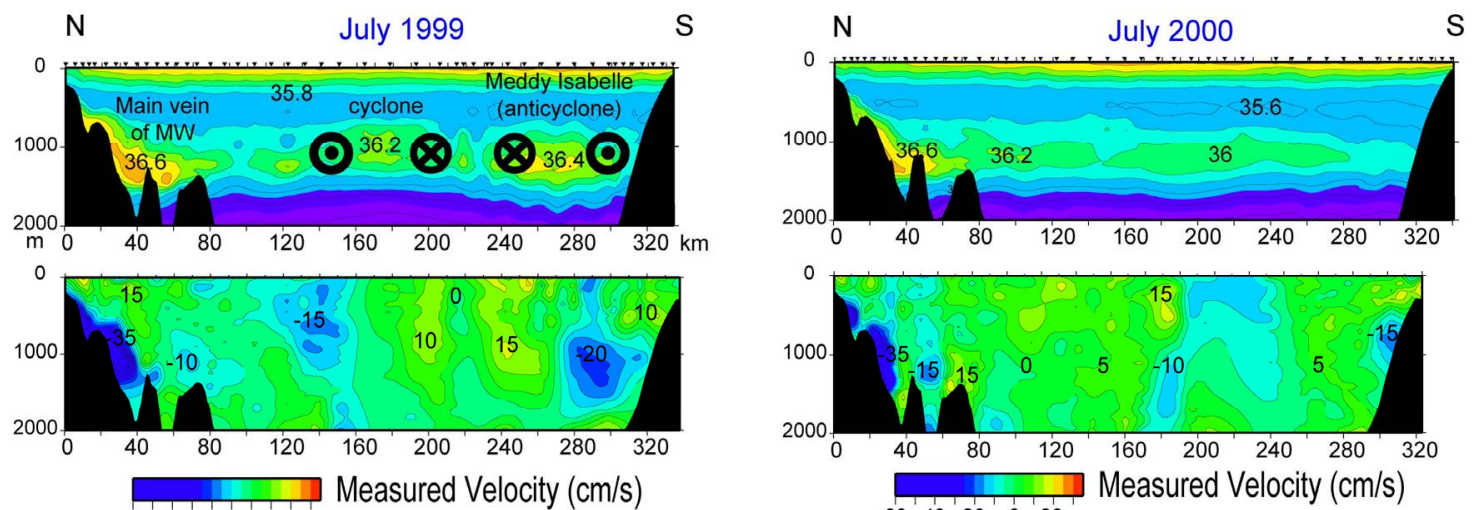

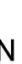

$-60-40-20 \quad 0 \quad 20$

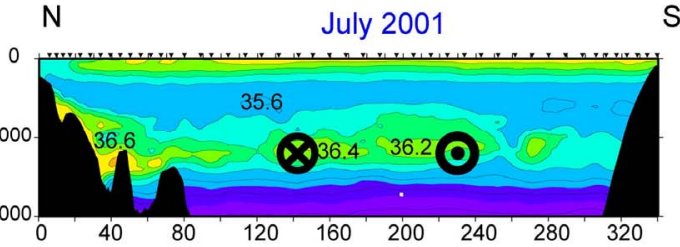

Seismic profile - SISMAR 23 (April 2001)

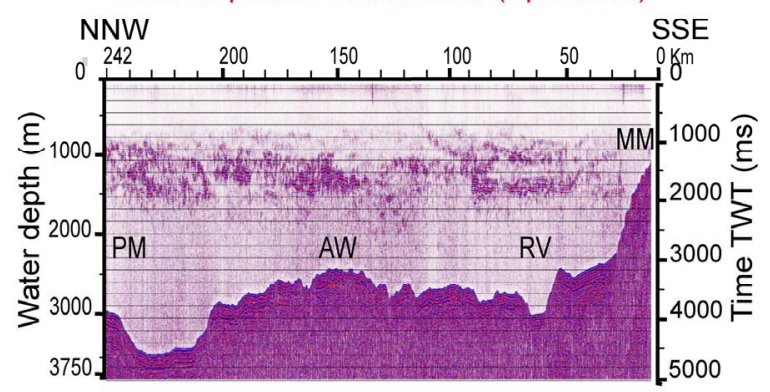

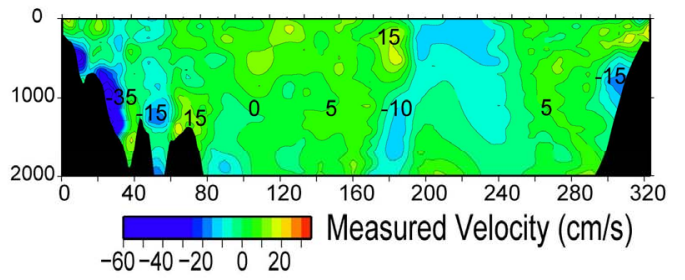

N

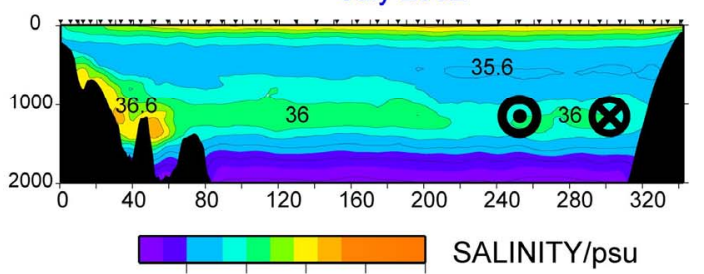

35.536 .036 .537 .037 .5

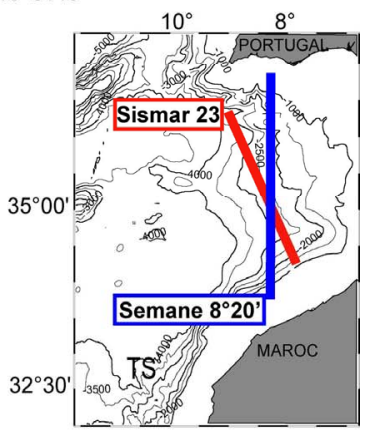

Figure 1. Upper six panels: salinity cross-sections along $8^{\circ} 20^{\prime} \mathrm{W}$ in the Gulf of Cadiz for years $1999,2000,2001,2002$ and LACDP velocity for 1999 and 2000, are presented. Triangles above the salinity sections indicate the position of each CTD's. Direction of oceanic currents are given by arrows made of a cross or a dot in a circle (cross/circle: current is W to E; dot/circle: current is $\mathrm{E}$ to $\mathrm{W}$ ). These directions are estimated from LADCP velocities for 1999 and 2000 and from geostrophic velocities calculated for 2001 and 2002 (Geostrophic velocity sections are not presented because they depend on an arbitrary level of no motion). Lower right panel: Location of the SEMANE (1999-2002) oceanographic sections (in blue) and of the SISMAR seismic section (in red). Lower left panel : Seismic reflectivity is shown along the SISMAR section acquired in April 2001.

nated from another meddy northwest of the two eddies of our section. This meddy detached in the Cape Saint Vincent area. North of the cyclone (between km 100 and 140) lies another submesoscale feature. Its salinity maximum is comparable to that of the cyclone and of the filament, but its velocity signature is rather anticyclonic (though it is weak). Considering its small diameter (about $30 \mathrm{~km}$ ) and its intensification near $1300 \mathrm{~m}$ depth, it appears to be a fragment detached from the lower undercurrent, which then adjusted an anticyclonic rotation to its density structure.

In the SEMANE 2000 data, a salty patch is detached from the undercurrents; it lies between km 150 and 280.
But the LADCP velocity section identifies an anticyclonic signature above this patch and only weak velocities in this patch. Furthermore, the maximum salinity (36) is rather low for a meddy (though such salinities might be observed at a meddy periphery).

In the SEMANE 2001 data, smaller and more marked

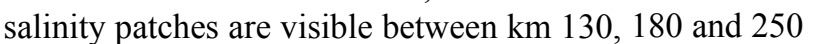
(a priori a split structure or two neighboring structures), and a smaller one between $\mathrm{km} 265$ and 285. Geostrophic velocity (with the bias due to the arbitrary level of no motion) indicates an anticyclonic signal for the whole structure between $\mathrm{km} 130$ and 250 (it would thus constitute a meddy with $60 \mathrm{~km}$ radius). Considering their ther- 
mohaline characteristics, these structures are likely to originate from undercurrent instabilities between Portimão Canyon and Cape Saint Vincent.

Finally, in the SEMANE 2002 data, two salty bodies are visible: a large one between $\mathrm{km} 80$ and 210 and a smaller one, detached from the undercurrents, between $\mathrm{km} 250$ and 300. The geostrophic velocity is anticyclonic in the northern part of the large patch (other measurements, not shown here, indicate that a meddy was intensified west of this section at this latitude). The southern structure is more likely a small cyclone.

The SISMAR 23 multi-channel seismic profile exhibits three main features:

- Between km 30 and 90 two layers of intense reflectors are found near 900 and $1400 \mathrm{~m}$ depth. These two layers are separated by a weakly reflecting, lens-like core. From these characteristics, we infer that this structure is a meddy, with homogeneous core waters, high temperature and salinity gradients above and below this core. Such a location for a meddy is compatible with the SEMANE 1999 observations.

- Between km 130 and 180 and between 900 and 1400 $\mathrm{m}$ depths, lies a thick stack of reflectors which also seems to form staircases. Since no strong reflector is found above or below this layer, we conclude that a dynamic structure, if it exists, must lie either completely above or completely below.

- Finally, between km 190 - 200 and 230, strong reflectors seem to circle a weakly reflecting, lens-like core. Though this feature is less clear than the southern one, we hypothesize that an anticyclonic structure lies there. Physically, this location is about mid-way between Portimão Canyon and Cape Saint Vincent and is known to be a site of meddy generation.

The TGS-NOPEC multi-channel seismic profiles exhibit three main features (see Figure 2):

- In the 707 profile, three lens-like structures are identified near the continental slope. Core $\mathrm{X}$ is a priori the upper MW undercurrent. Lens $\mathrm{Y}$ is probably an anticyclonic structure recently detached from the slope. Lens $\mathrm{Z}$ is a priori a fragment of the shallow MW undercurrent.

- In the 808 profile, dipping reflectors are identified on the continental slope and surround the MW flow.

- Strong reflectors are identified above and below the MW cores (at 500 and $1500 \mathrm{~m}$ depth) and offshore of the MW undercurrents at about $1000 \mathrm{~m}$ depth.

The acoustic impedance contrasts in the ocean are determined by temperature and salinity gradients between the different water masses. This renders seismic oceanography sections sensitive to the frequency bandwidth, which is largely determined by the seismic source function. Work by Hobbs et al. [19] shows that frequencies around $20 \mathrm{~Hz}$ are most appropriate to delineate large impedance contrasts which occur over a vertical scale of tens of meters, whereas frequencies around $60 \mathrm{~Hz}$ image boundary layers of about $10 \mathrm{~m}$ thickness. To provide a comprehensive seismic image of water masses would require broadband data from less than $10 \mathrm{~Hz}$ to more than $200 \mathrm{~Hz}$. The low frequency data we have, best delineate the boundary of the Meddy and of the undercurrents.

The SEMANE 2001 section (in Figure 2) shows that, between 600 and $1600 \mathrm{~m}$ depths, the salinity minimum in the Mediterranean Water undercurrents is 35.6 and that the salinity maximum is 36.4 .

These values of minima and maxima are also found in the vertical profile of salinity in the southern meddy of SEMANE 1999, shown in Figure 3. In this latter figure, it can also be seen that temperature decreases from $11.5^{\circ} \mathrm{C}$ to $7^{\circ} \mathrm{C}$ between 1200 and $1600 \mathrm{~m}$ depth. In this depth range, we observe the homogeneous layers previously mentioned with large thermohaline staircases (staircases are also observed above the meddy).

\section{Synthetic Reflectivity and Wavelet Analysis of the MW Structures}

Acoustic wave reflections in the water column are induced by acoustic impedance contrasts. Therefore we calculated a synthetic vertical gradient of acoustic impedance from the SEMANE hydrological data, for comparison with the SISMAR seismic reflectivity data. Acoustic impedance is $I=\rho . c$ where $\rho$ is the seawater density and $\mathrm{c}$ the sound speed. Reflectivity $\mathrm{Z}$ was calculated from hydrology via $Z=\mathrm{dI} / \mathrm{dz}$.

Figure 4 shows synthetic reflectivity calculated from SEMANE 2001 data and real seismic reflectivity extracted from SISMAR23 data. Synthetic reflectivity presents a strong amplitude between 800 and $1400 \mathrm{~m}$ depth whereas real seismic reflectivity shows large values between 700 and $1300 \mathrm{~m}$ depth. We note that the vertical gradient of sound speed is dominant in the synthetic reflectivity signal. Intense sound speed gradients are also identified in the SEMANE data.

Then we performed a wavelet analysis on vertical profiles of these variables across the mesoscale and submesoscale features of the 1999 section. The analysis is a Continuous Wavelet Analysis modified from Grinsted et al. [20] using a Morlet wavelet with a vertical reference wavenumber equal to 6 ; this value was chosen to provide a good balance between distance and frequency localization. The continuous Wavelet Transform (CWT) can be seen as a consecutive series of band-pass filters applied to the depth series where the wavelet scale is linearly related to the characteristic period of the filter. The CWT 


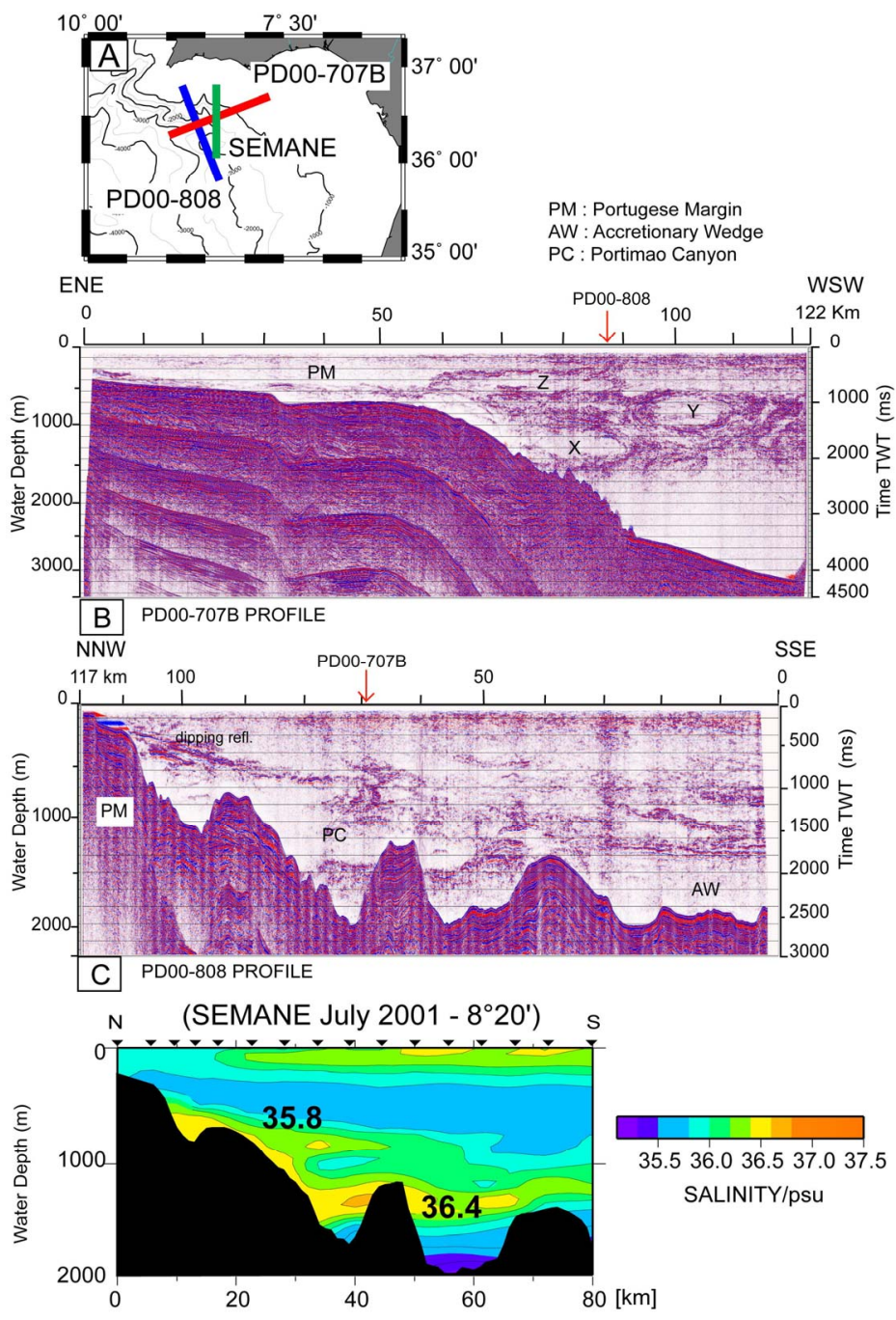

Figure 2. Upper left (A): Location of the TGS-NOPEC seismic profiles (April 2000). Middle panel (B): seismic profile PD00-707B with 3 water bodies X, Y and Z. Lower panel (C): seismic profile PD00-808, presenting dipping reflectors on the slope. D: Salinity section (SEMANE 2001) across the continental slope imaging the MW undercurrents.

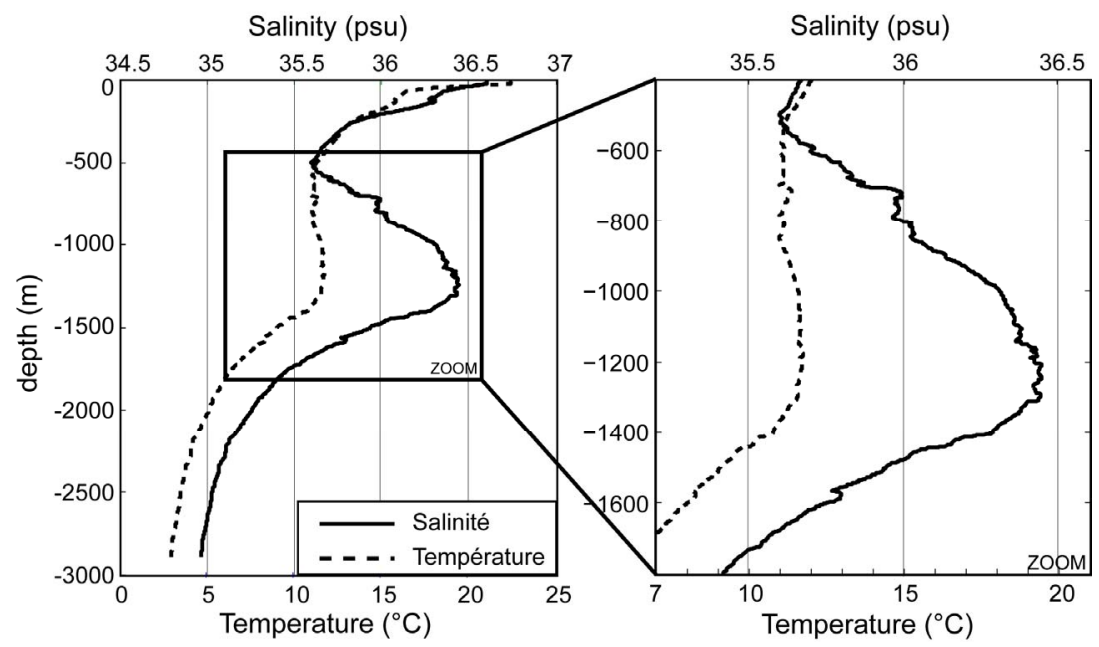

Figure 3. Left: Vertical profiles of temperature (dotted line) and salinity (solid line) across the southern meddy of SEMANE 1999. Right : Zoom on the 500 - $1700 \mathrm{~m}$ depth interval showing the homogeneous layers in temperature and in salinity. 

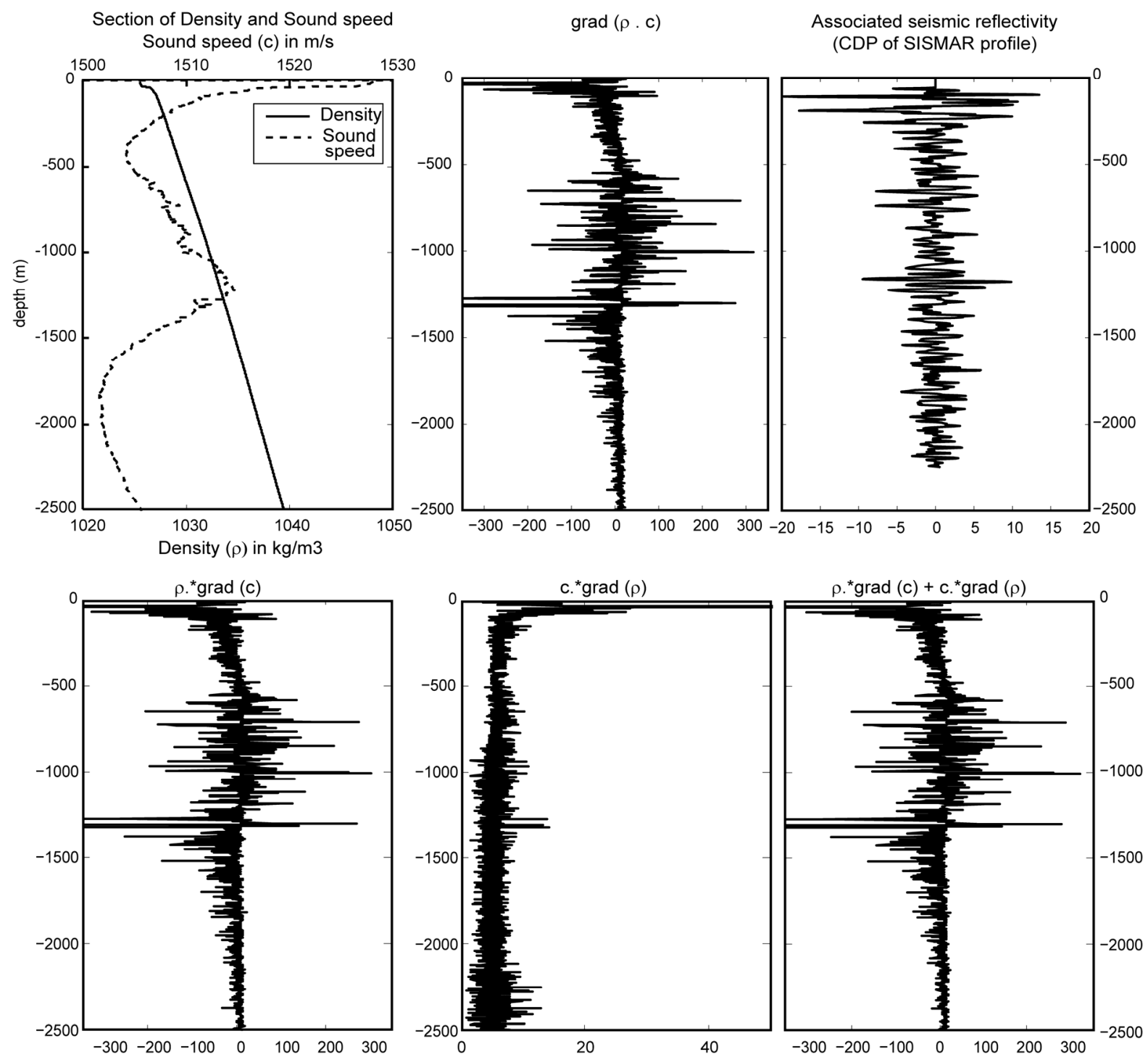

Figure 4. Top left: Vertical profiles of density and celerity across the meddy of SEMANE 2001. Top middle: Vertical profile of gradient of density * celerity calculated from temperature and salinity. Top right: Seismic reflectivity of the associated CDP (seismic profile: SISMAR 23 (April 2001)). Bottom: Vertical profiles of the two components of impedance gradient and of their sum.

has edge artifacts because the wavelet is not completely localized in depth.

\subsection{Vertical Wavelet Transform in the MW Tongue}

Figure 5 shows the wavelet transform of two vertical profiles; the synthetic reflectivity calculated from hydrological data, and reflectivity from real seismic data. Both profiles are located in the MW tongue in the Gulf of Cadiz, but they were not obtained at the same time. The main vertical contrasts are due the sound speed gradients.

For the seismic data, strong signals are located near the surface (100 - $500 \mathrm{~m}$ depths), at 700, 1000 and 1200 m depths with wavelengths mainly between 12 and $92 \mathrm{~m}$. For the hydrological data, vertical contrasts are located near the surface, at 700, 1000 and $1300 \mathrm{~m}$ depth with wavelengths between 8 and $64 \mathrm{~m}$. The shorter wavelengths obtained with CTD data are a priori due to the higher vertical resolution of hydrological measurements. Near the ocean surface, the seismic reflectivity is more marked than that computed from hydrological data. This structure may be related to the source wavelet of the SISMAR data (which we do not have). The fact that the bottom of the MW tongue is not located exactly at the same depth by the hydrological data and by the seismic data indicates changes in MW structure from spring to summer. 


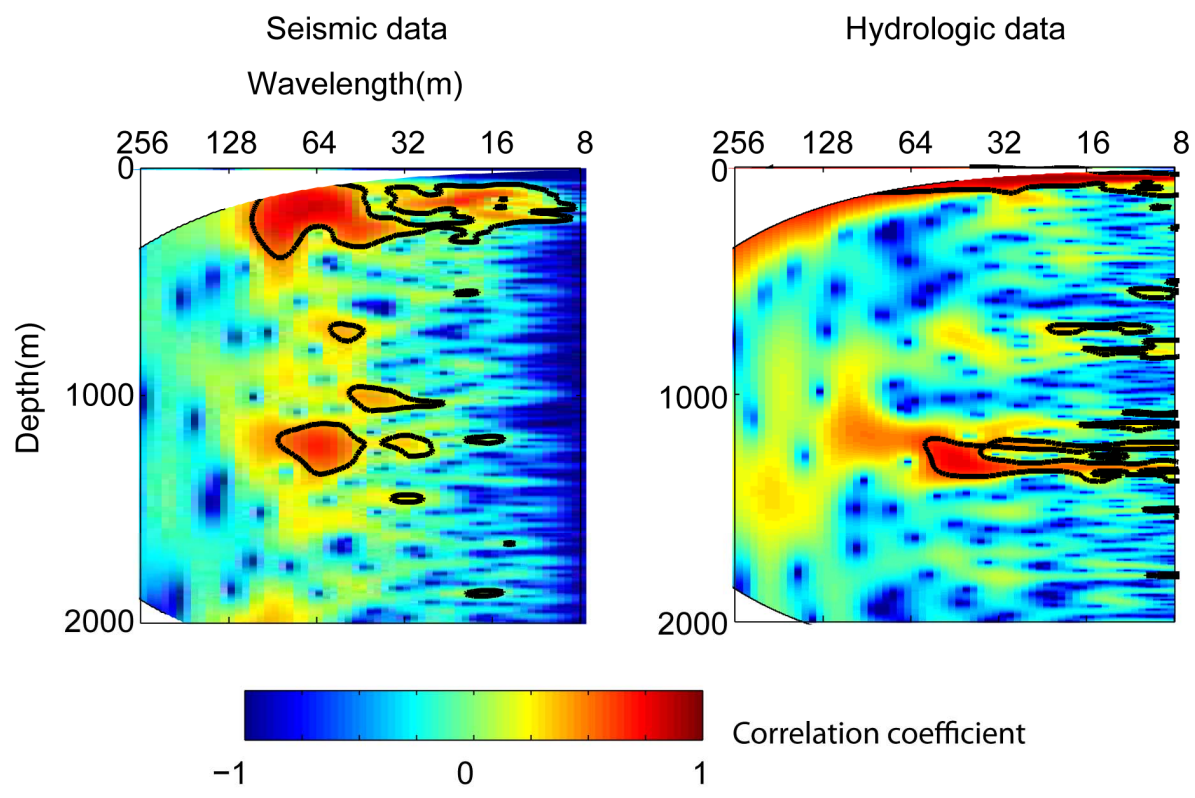

Figure 5. Vertical wavelet analysis of seismic reflectivity (CDP of a SISMAR stack) and synthetic reflectivity calculated from hydrological data (CTD of SEMANE 2002). Data were collected through the tongue of MW in the Gulf of Cadiz. The vertical wavelength and the depth are given in meters. The thick black contour designates the $5 \%$ significance level against red noise and the cone of influence (COI) where edge effects might distort the picture is shown as a lighter shade. Scale defined to blue $(-1)$ from red (1) is the normalized correlation coefficient.

\subsection{Vertical Wavelet Transform in Mesoscale and Sub-Mesoscale Structures}

Figure 6 shows the salinity cross-section of 1999 and the vertical wavelet transforms of synthetic reflectivity across several mesoscale and submesoscale structures on that section. Along the Meddy axis, the strongest signals of reflectivity are located near the surface, between 600 and $800 \mathrm{~m}$ and between 1200 and $1800 \mathrm{~m}$ depths, with wavelengths mainly between 8 and $64 \mathrm{~m}$. This reflectivity is located at the depths of the thermohaline staircases. For the cyclone, the reflectivity signal is intensified in the lower part of the structure, between 900 and $1700 \mathrm{~m}$ depths, with wavelengths from 8 to $64 \mathrm{~m}$. Thermohaline contrasts are more marked at these depths for this cyclone. For the sub-mesoscale structure, the reflectivity is concentrated near $1500 \mathrm{~m}$ depth (its lower boundary), with vertical wavelengths between $8-64 \mathrm{~m}$. The filament has vertical gradients comparable with those of the cyclone.

\subsection{Wavelet Analysis of Real and Synthetic Reflectivity Profiles in a Meddy}

Figure 7 compares the vertical wavelet transform of real seismic reflectivity (a CDP of SISMAR 23) and that of a synthetic reflectivity profile (calculated from a CTD of SEMANE 2001); these profiles do not match in space nor time, but both correspond to a meddy. Structures in the seismic data have vertical wavelengths between 12 and $92 \mathrm{~m}$. The synthetic data have wavelengths between 8 and $64 \mathrm{~m}$. The shorter wavelengths may again be attributed to the higher vertical resolution of CTD data than that of seismic profiles. Both signals exhibit strong reflectivity at the base of the meddy, but the synthetic data also have strong reflectivity at the upper boundary of the meddy. Below the sea surface, reflectivity is observed more intensely by seismic measurements.

\subsection{Acoustic Reflectivity across the MW Undercurrents}

Figure 8 shows the vertical gradient of acoustic impedance across the MW undercurrents and its wavelet analysis. The main vertical contrasts are due to the sound speed gradients and are located near the surface and between 600 and $1200 \mathrm{~m}$ depth with wavelengths between 8 and $128 \mathrm{~m}$. Between 600 and $1000 \mathrm{~m}$ depths wavelengths are mainly of $128 \mathrm{~m}$. This wavelength is related to the thickness of the MW undercurrents themselves. The shorter wavelengths near $1200 \mathrm{~m}$ depth are related to thermohaline staircases below these undercurrents.

\section{Conclusions}

The hydrological data of the SEMANE experiments shows a diffuse tongue of Mediterranean Water across the Gulf of Cadiz with a salinity of about 36 . Mesoscale 
$\mathrm{N}$

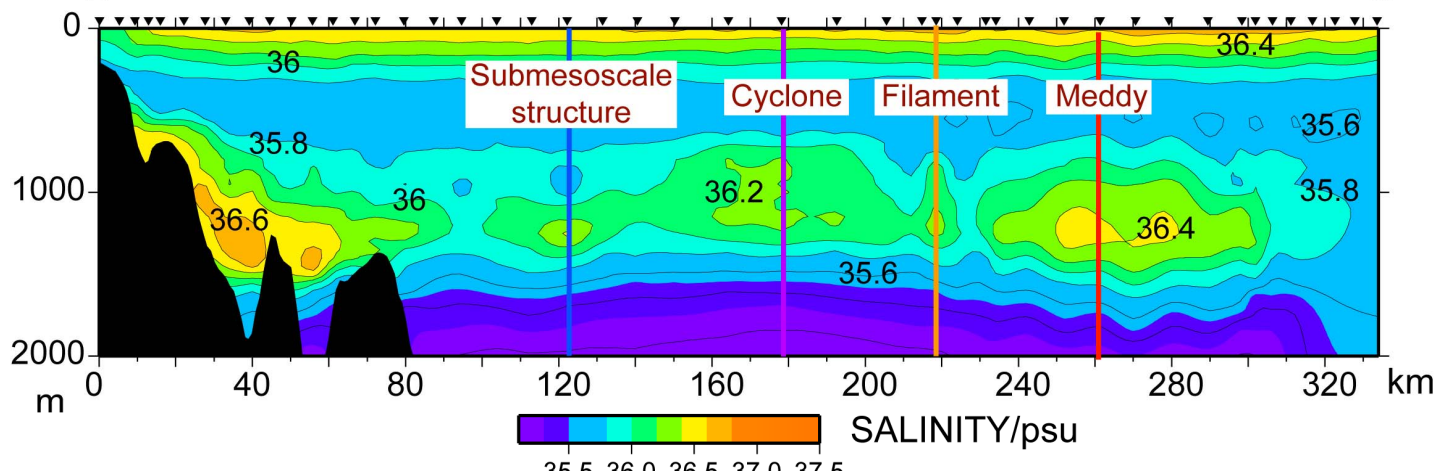

35.536 .036 .537 .037 .5

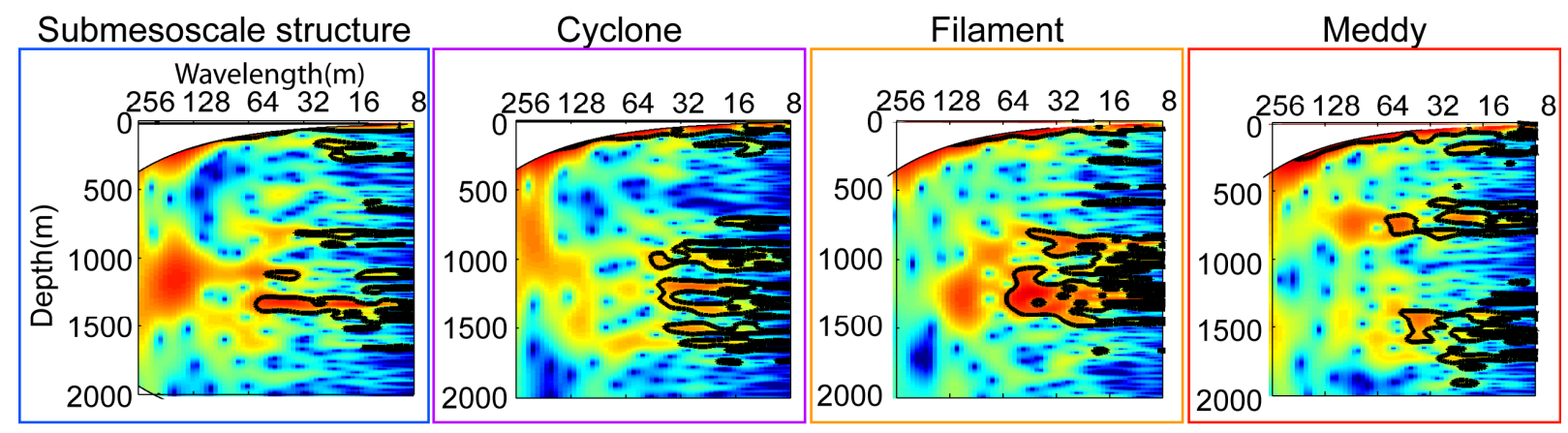

\begin{tabular}{lll}
\hline & Correlation coefficient
\end{tabular}

Figure 6. Upper plot : Salinity cross section along $8^{\circ} 20^{\prime} \mathrm{W}$ in the Gulf of Cadiz from SEMANE 1999. This section identifies the four structures which are then analysed via wavelets. Lower four plots: Wavelet analysis of vertical gradients of reflectivity through the meddy, the cyclone, the submesoscale structure and the filament of the SEMANE 1999 hydrological section. The dashed curve at the bottom of each plot bounds the region of confidence for wavelet analysis (this region lies above the curve). Wavelengths are as in Figure 3.

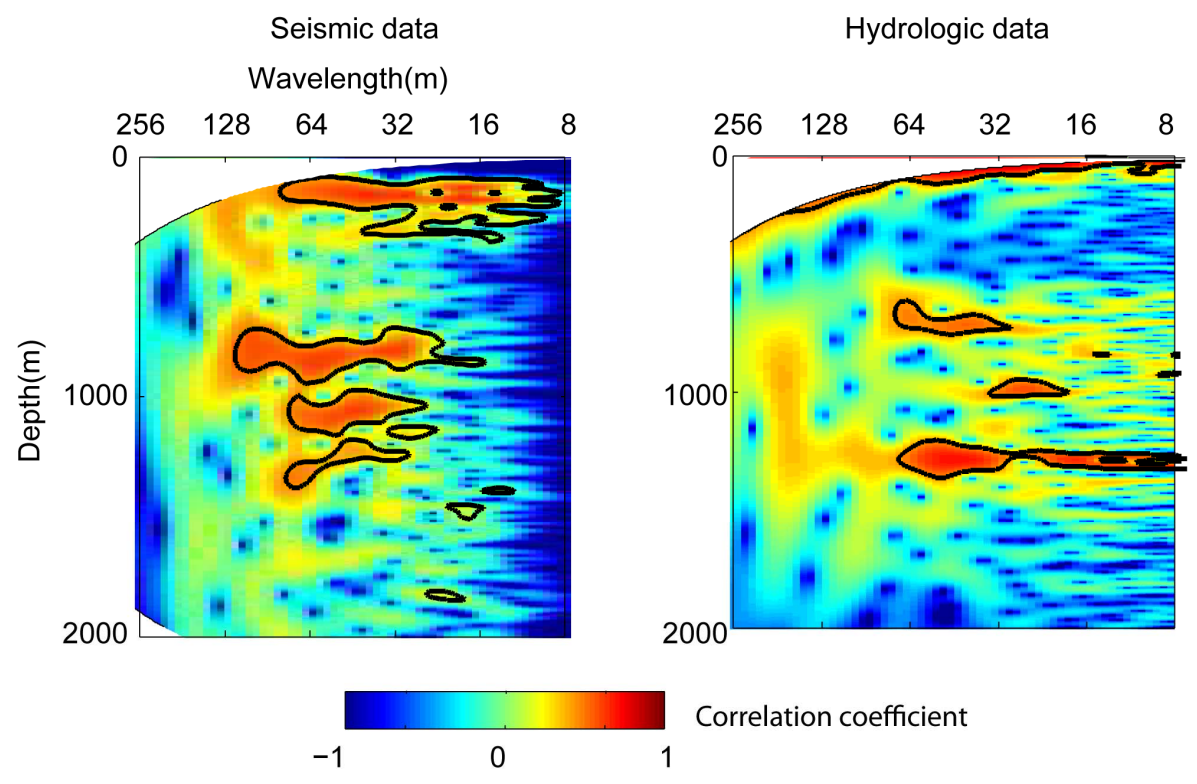

Figure 7. Vertical wavelet analysis of a real seismic reflection profile (CDP of stack SISMAR 23) co-located with a synthetic reflectivity profile (calculated from SEMANE 2001 CTD data) through meddies. The dashed line indicates the limit of confidence for wavelet analysis. Wavelegths are as in Figure 3. 

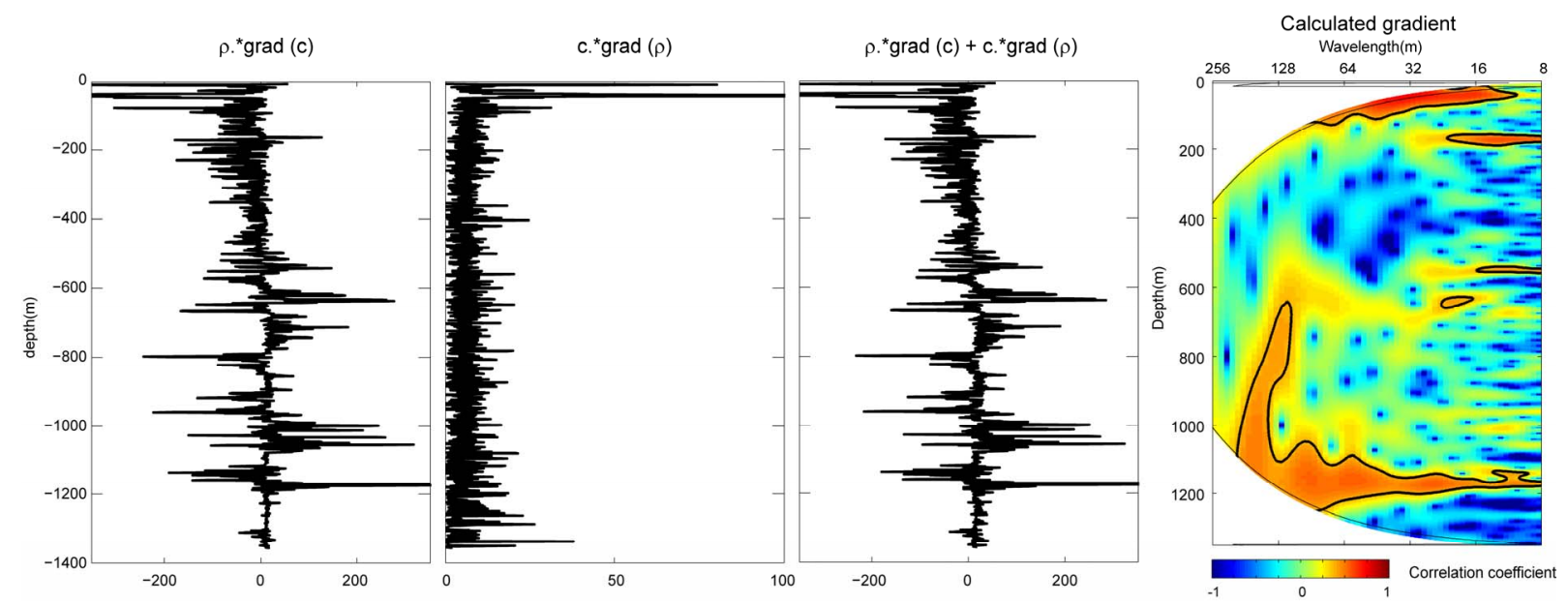

Figure 8. The two components of the synthetic reflectivity signal (calculated from SEMANE 1999 CTD data) through the MW undercurrent, their sum, and it vertical wavelet analysis. The dashed line indicates the limit of confidence for wavelet analysis. Wavelengths are as in Figure 3.

structures of Mediterranean Water (meddies, cyclone) are observed south of Portimão Canyon, as well as submesoscale structures (filaments, small eddies). The mesoscale structures originate from the instability of the undercurrents between Portimão Canyon and Cape Saint Vincent, but the smaller scale structures can originate both from the undercurrents (small eddies) or from the mesoscale eddies (filaments). Below and above the meddies, thermohaline staircases are observed (see also [21]).

Both synthetic and real reflectivity data exhibit reflectors above and/or below the mesoscale and submesoscale structures with wavelengths of $8-64 \mathrm{~m}$ approximately, but the real seismic data display these reflectors more intensely in the near surface layer; conversely, the synthetic data indicate shorter vertical wavelengths due to the high resolution of CTD measurements. The very thin hydrological structures observed via hydrology are related to diffusive structures or to fine-scale turbulence. The reflectors in seismic data correspond to the strong gradients in temperature and salinity at the interfaces of the $8-64 \mathrm{~m}$ thick homogeneous layers observed in hydrology.

Meddies and filaments have reflectors at their upper and lower boundaries, but cyclones and submesoscale eddies have more intense reflectors at their base. For MW undercurrents, strong reflectors are found around them. With their fine horizontal resolution, seismic reflection data can help identify submesoscale structures of Mediterranean Water which are difficult to locate only via hydrology; conversely, hydrology provides finer vertical resolution. Indeed, the vertical resolution of seismic data used here is limited by its frequency and its timesampling. Historical databases of seismic measurements in the Gulf of Cadiz should be revisited to identify eddies and to compute turbulent fluxes of the MW from the coast.

\section{Acknowledgements}

Special thanks are due to Dr J. Paillet who originally designed the $8.20 \mathrm{~W}$ section. The authors of the present paper wish to thank the captain and crew of the RRS Discovery and of the RV D'Entrecasteaux and Laperouse, as well as SHOM and GO partners.

\section{References}

[1] I. Ambar and M. R. Howe, "Observations of the Mediterranean outflow-1 Mixing in the Mediterranean Outflow," Deep Sea Research Part A. Oceanographic Research Papers, Vol. 26, No. 5, 1979, pp. 535-554. doi:10.1016/0198-0149(79)90095-5

[2] I. Ambar and M. R. Howe, "Observations of the Mediterranean outflow-2 the deep circulation in the vicinity of the Gulf of Cadiz," Deep Sea Research Part A. Oceanographic Research Papers, Vol. 26, No. 5, 1979, pp. 555-568. doi:10.1016/0198-0149(79)90096-7

[3] F. Madelain, "Influence de la topographie du fond sur l'écoulement Méditerranéen entre le Détroit de Gibraltar et le Cap Saint-Vincent," Cahiers Oceanographiques, Vol. 22, 1970, pp. 43-61.

[4] L. Chérubin, A. Serpette, X. Carton, J. Paillet, O. Connan, P. Morin, R. Rousselet, B. Le Cann, P. Le Corre, T. Labasque, D. Corman and N. Poete, "Descriptive Analysis of the Hydrology and Currents on the Iberian Shelf from Gibraltar to Cape Finisterre: Preliminary Results from the Semane and Interafos Experiments," Annales Hydrographiques, Vol. 21, No. 768, 1997, pp. 5-81.

[5] N. Serra, I. Ambar and R. H. Käse, "Observations and Numerical Modelling of the Mediterranean Outflow Splitting and Eddy Generation," Deep Sea Research Part II: Topical Studies in Oceanography, Vol. 52, No. 3-4, 
2005, pp. 383-408. doi:10.1016/j.dsr2.2004.05.025

[6] N. Serra and I. Ambar, "Eddy Generation in the Mediterranean Undercurrent," Deep Sea Research Part II: Topical Studies in Oceanography, Vol. 49, No. 19, 2002, pp. 4225-4243.

[7] I. Ambar, N. Serra, F. Neves and T. Ferreira, "Observations of the Mediterranean Undercurrent and Eddies in the Gulf of Cadiz during 2001," Journal of Marine Systems, Vol. 71, No. 1-2, 2008, pp. 195-220. doi:10.1016/j.jmarsys.2007.07.003

[8] N. Serra, S. Sadoux, I. Ambar and D. Renouard, "Observations and Laboratory Modeling of Meddy Generation at Cape St. Vincent," Journal of Physical Oceanography, Vol. 32, No. 1, 2002, pp. 3-25. doi:10.1175/1520-0485(2002)032<0003:OALMOM $>2.0$. $\underline{\mathrm{CO} ; 2}$

[9] W. Zenk, K.L. Schultz-Tokos and O. Boebel, "New Observations of Meddy Movement South of the Tejo Plateau," Geophysical Research Letters, Vol. 12, No. 24, 1992, pp. 2389-2392. doi:10.1029/92GL02139

[10] J. Paillet, B. Le Cann, A. Serpette, Y. Morel and X. Carton, "Real-time Tracking of a Northern Meddy in 1997-1998," Geophysical Research Letters, Vol. 26, No. 13, 1999, pp. 1877-1880. doi:10.1029/1999GL900378

[11] J. Paillet, B. Le Cann, X. Carton, Y. Morel and A. Serpette, "Dynamics and Evolution of a Northern Meddy," Journal of Physical Oceanography, Vol. 32, No. 1, 2002, pp. $55-79$.

doi:10.1175/1520-0485(2002)032<0055:DAEOAN $>2.0$. $\mathrm{CO} ; 2$

[12] X. Carton, L. Chérubin, J. Paillet, Y.Morel, A. Serpette and B. Le Cann, "Meddy coupling with a deep cyclone in the Gulf of Cadiz," Journal of Marine Systems, Vol. 32, No. 1-3, 2002, pp. 13-42. doi:10.1016/S0924-7963(02)00028-3

[13] X. Carton, N. Daniault, J. Alves, L. Cherubin and I. Ambar, "Meddy dynamics and interaction with neighboring eddies southwest of Portugal: observations and modeling," Journal of Geophysical Research, Vol. 115, No. C6,
2010, p. C06017. doi:10.1029/2009JC005646

[14] W. S. Holbrook, P. Paramo, S. Pearse and R. W. Schmitt, "Thermohaline Fine Structure in an Oceanographic Front from Seismic Reflection Profiling," Science, Vol. 301, No. 5634, 2003, pp. 821-824. doi:10.1126/science. 1085116

[15] P. Nandi, W. S. Holbrook, S. Pearse, P. Paramo and R. W. Schmitt, "Seismic Reflection Imaging of Water Mass Boundaries in the Norwegian Sea," Geophysical Research Letters, Vol. 31, 2004, p. L23311. doi:10.1029/2004GL021325

[16] E. Thiébot and M.-A. Gutscher, "The Gibraltar Arc seismogenic zone (part 1): Constraints on a Shallow East Dipping Fault Plane Source for the 1755 Lisbon Earthquake Provided by Seismic Data, Gravity and thermal Modeling, Tectonophysics, Vol. 426, No. 1-2, 2006, pp. 135-152. doi:10.1016/j.tecto.2006.02.024

[17] Ö. Yilmaz, "Seismic Data Processing," In: E. Neitzel, B. Stephen, M. Doherty, Eds, Investigations in Geophysics, Society of Exploration Geophysics, Tulsa, 1987.

[18] R. J. J. Hardy and R. W. Hobbs, "Multiple Suppression in Deep Water," AGU Geodynamics Series, Vol. 22, 1991, pp. 383-390.

[19] R. W. Hobbs, D. Klaeschen, V. Sallares, E. Vsemirnova and C. Papenberg, "The Effect of Seismic Source Bandwidth on Reflection Sections to Image Water Structure," Geophysical Research Letters, Vol. 36, 2009, pp. 1-5.

[20] A. Grinsted, J. C. Moore and S. Jevrejeva, "Application of the Cross Wavelet Transform and Wavelet Coherence to Geophysical Time Series," Nonlinear Processes in Geophysics, Vol. 11, 2004, pp. 561-566. doi:10.5194/npg-11-561-2004

[21] E. Quentel, X. Carton, M. A. Gutscher and R. Hobbs, "Detecting and Characterizing Mesoscale and Submesoscale of Mediterranean Water from Joint Seismic and Hydrographic Measurements in the Gulf of Cadiz," Geophysical Research Letters, Vol. 37, 2010. doi:10.1029/2010GL042766 